\title{
Ethnic differences in mental health among incarcerated youths: do Moroccan immigrant boys show less psychopathology than native Dutch boys?
}

\author{
Violaine Veen • Gonneke Stevens • Theo Doreleijers • \\ Jan van der Ende · Wilma Vollebergh
}

Received: 14 April 2009/Accepted: 16 October 2009/Published online: 22 November 2009

(C) The Author(s) 2009. This article is published with open access at Springerlink.com

\begin{abstract}
Psychiatric disorders are highly prevalent among incarcerated youth. However, whereas ethnic minority youths are overrepresented in the juvenile justice system, limited research is available on their mental health. In this study, differences in mental health problems between incarcerated adolescents of native Dutch and Moroccan origin, were examined. Child Behavior Checklist and Youth Self-Report scores were compared between incarcerated adolescents of native Dutch and Moroccan origin. Their scores were also compared to those of native Dutch and Moroccan immigrant youths in the general, nonincarcerated population. Native Dutch incarcerated adolescents showed higher levels of various mental health problems than incarcerated adolescents with a Moroccan background. Compared to the general population, incarcerated youths showed higher levels of mental health problems, but this deviation was much larger for native
\end{abstract}

\section{Veen $(\bowtie)$}

Utrecht University, Utrecht, The Netherlands

e-mail: v.veen@uu.nl

G. Stevens · W. Vollebergh

Department of Interdisciplinary Social Sciences,

Utrecht University, Utrecht, The Netherlands

T. Doreleijers

VU University Medical Center, Amsterdam,

The Netherlands

T. Doreleijers

Faculty of Law, Leiden University, Leiden,

The Netherlands

J. van der Ende

Department of Child and Adolescent Psychiatry,

Erasmus Medical Center Rotterdam/Sophia Children's Hospital,

Rotterdam, The Netherlands
Dutch than for Moroccan immigrant youths. These ethnic differences in mental health problems could not be explained by ethnic differences in socio-economic background and social desirable answering tendencies. Incarcerated youths of Moroccan origin show less psychopathology than incarcerated native Dutch youths, which might be explained by disparities in sentencing procedures.

Keywords Mental health - Incarcerated youth . Ethnic differences

\section{Introduction}

The prevalence of psychiatric problems among incarcerated youths is extremely high $[1,29]$. Nearly two-third of the male juvenile detainees has one or more psychiatric diagnoses, even after excluding disorders that include delinquent behaviour [21, 30]. Substance use, ADHD and behavioural disorders are the most prevalent, and approximately half of the incarcerated adolescents in the US has an affective or anxiety disorder [1]. In addition, adolescents in detention and correctional facilities are about ten times more likely to suffer from psychosis than the general adolescent population [9].

However, whereas ethnic minority youths are overrepresented in the juvenile justice system [17], limited research is available on ethnic differences in mental health problems among incarcerated youths [21, 24, 29, 30]. Some US studies examined ethnic differences in prevalence rates of psychiatric diagnoses. It was generally found that incarcerated African-American youths have lower rates of psychiatric disorders such as disruptive behaviour disorder and substance use disorder, and lower rates of co-morbidity 
than Caucasians $[1,21]$. Studies using self-report instruments also found that Caucasian youth in the juvenile justice system report more psychiatric symptoms than ethnic minority youth. Caucasians generally reported higher levels of substance use, somatic complaints, suicide ideation and angry-irritable symptoms [7], social problems, thought problems, externalizing behaviour [11] and higher levels of mental health distress [24] than ethnic minority youths in juvenile justice settings. A meta-analysis on selfreported symptoms indicated that incarcerated Caucasians are more likely to report substance use problems and suicide ideation than incarcerated ethnic minority youths [29].

In sum, the available research shows that incarcerated ethnic minority youths overall show lower levels of mental health problems than incarcerated ethnic majority youths. However, these studies do not warrant general conclusions, which is due to several limitations. First, European research on mental health problems of incarcerated ethnic minority youth is scarce [10,30], which is problematic since the characteristics of ethnic minority populations in Western Europe are largely incomparable to those of minority populations in the US [19]. Second, to date, none of the research used a comparison group consisting of nonincarcerated minority and majority youth. Yet, it is essential to have information on mental health problems in general population youths, because it enables us to examine the extent to which the level of mental health problems in both ethnic incarcerated groups deviates from this level in the respective general populations. Third, former studies did not include parent-reported data. The parental perspective may enrich our knowledge on mental health problems in incarcerated youth [31].

The present study examines ethnic differences in selfand parent-reported mental health problems among ethnic minority and majority youths in the incarcerated and the general, non-incarcerated population in the Netherlands. The study focuses on youths of native Dutch origin and youths belonging to one of the largest ethnic minority groups in the Netherlands, the Moroccans. Dutch police records show that Moroccan adolescents, in comparison to both native Dutch and other ethnic minorities, are overrepresented in juvenile justice settings [5]. A quarter of the population of young offenders in juvenile justice institutions is of Moroccan origin, while Moroccans represent only $2 \%$ of the general Dutch population [6]. Since youth detained under criminal law in juvenile justice institutions merely consists of male detainees, the present study focuses only on boys.

Two research questions are addressed. Are there differences in the level and the character of mental health problems between native Dutch and Moroccan immigrant incarcerated boys? And to what extent do the scores of both groups of incarcerated boys deviate from the scores in the respective general populations? The latter question enables us to take into account the baseline level of mental health problems in the general populations of both ethnic groups. We expect that the prevalence of self- and parent-reported mental health problems is higher among both native Dutch and Moroccan immigrant incarcerated adolescents than among youths in the general population. In addition, in line with previous research in the US, we expect that native Dutch incarcerated adolescents and their parents report higher levels of mental health problems than incarcerated boys of Moroccan origin and their parents.

\section{Method}

Participants

\section{Incarcerated youth sample}

Participants consisted of 298 boys aged 12-18 years who were consecutively taken into pre-trial detention in 10 (out of 11) juvenile justice institutions in the Netherlands between May 2006 and February 2008. In the Netherlands, criminal legislation for youths only applies to persons aged 12-18 [30]. Pre-trial detention is enforced when a youngster is suspect of an offence, awaiting trial and if detention is thought to be necessary for the protection of others or the child itself.

In order to approach the participants, the researchers weekly received an overview from The Dutch Ministry of Justice, containing information on all adjudicated adolescents who were placed in pre-trial detention in a juvenile justice institution in the prior week. Eligible for inclusion were those adolescents who were of Moroccan or Dutch native origin (i.e., for the Moroccan adolescents this meant that at least one of their parents had to be born in Morocco, for the native Dutch that both parents were born in the Netherlands), who remained in the juvenile justice institution for over a week, and who were allowed to receive a visitor. Adolescents had to be able to read and speak Dutch. Adolescents with intellectual disabilities, as registered by the institutional workers of the juvenile justice institution, were excluded from the sample. The adolescents received a letter which contained information on the purpose of the interview and were asked to participate in the study by an employee of the juvenile justice institution. If the adolescent consented to participation, an appointment was made for an interview (consisting of both interview components and self-report questionnaires such as the Youth SelfReport, version 1991 [2]) at the juvenile justice institution. Four hundred and seventy-six incarcerated adolescents were asked to participate in the study, 315 incarcerated adolescents were interviewed (total response rate $66 \%$, 
response rate native Dutch boys $73 \%$, response rate Moroccan boys $62 \%$ ), and 17 interviews were found to be incomplete, leaving 298 complete interviews.

Because the percentage of 12-year olds in the incarcerated sample was much smaller (three boys) than in the general population samples, the data of these boys were left out of the analyses. This resulted in a total of 296 boys in the present study. Adolescents were all suspect of one or more offences (as formulated in youth criminal law), ranging from property offences to sexual offences, violent offences and arson. The mean age of all participants when they were incarcerated for their first offence was 15.9 years. Moroccan participants were incarcerated for their first offence at a mean age of 15.7 years, and Dutch participants at a mean age of 16.2 years. Hundred and forty-one adolescents (47\%) were of Moroccan origin (of $93 \%$ both parents were born in Morocco, of $7 \%$ one of the parents was born in Morocco). Nineteen percent of the Moroccan adolescents was born in Morocco, the others were born in the Netherlands. The remainder of the sample (53\%) consisted of 158 Dutch native adolescents.

Of the incarcerated boys who completed the interview, 273 parents were asked to participate in the study (24 parents could not be asked to participate because their addresses were unavailable, they moved, or their son did not give permission for his parent to participate in this study). Eighty-four parents refused to participate and 22 parents were not found at home by the interviewers. Onehundred and sixty-eight parents consented to participation in the study (total response rate $62 \%$, response rate Dutch parents $50 \%$, response rate Moroccan parents $70 \%$ ). For five parents data were found to be incomplete and were not further used in the analyses. Of the 163 completed interviews, 76 interviews were with native Dutch parents and 87 interviews were with parents of Moroccan origin. All parents received a letter containing the aims of the present study. Moroccan parents were sent an introductory letter in Dutch and Moroccan-Arabic and within a couple of weeks a trained Moroccan interviewer visited the parents' home to ask them to participate. Dutch parents were contacted by telephone to make an appointment for the interview. Dutch parents had to be able to speak and read Dutch. All parents completed the Child Behavior Checklist, version 1991.

Parent and adolescent participants were assured of the confidentiality of their spoken and written responses and data were archived anonymously. Moreover, written informed consent was obtained from the participants. Participants received compensation, adolescents received telephone cards which they could use within the juvenile justice institution and parents received a gift certificate. The research protocol was approved by the Ethical Board of the Department of Social Sciences and the Ministry of Justice in the Netherlands.
Moroccan immigrant general population sample

Youth Self-report (1991) and Child Behavior Checklist (1991) data were used of parent and adolescent interviewpairs originating from a larger study, in which a sample of 1,127 children aged 4 through 18 with at least 1 parent born in Morocco, were randomly selected from municipal registers of Rotterdam and The Hague. Data collection took place from April 2001 to July 2002. A total of 819 parents participated in the study (response rate $73 \%$ ) and $91 \%$ of the approached adolescents consented to participation. The data collection procedure and in- and exclusion criteria are described in detail elsewhere [18]. In the present study we only used data of male adolescent participants, aged 13 through $18(N=142)$.

\section{Dutch general population sample}

We used Youth Self-report (2001) and Child Behavior Checklist (2001) [3] data of parent and adolescent interview-pairs originating from a larger study performed in the Dutch province of Zuid-Holland (including Rotterdam and The Hague). Data collection took place between December 2003 and April 2005. Of the 2,317 eligible children aged 6 through 18 , who were randomly selected from municipal registers, $74 \%$ parents participated $(N=1,710)$. Of the adolescent participants, $20 \%$ were of non-Dutch origin (at least one parent born outside the Netherlands). The data collection procedure and in- and exclusion criteria are described in detail elsewhere [22, 23]. In the present study, we only used data of male adolescent participants aged 13 through 18, whose parents were both born in the Netherlands $(N=304)$.

\section{Measures}

\section{Emotional and behavioural problems}

The Youth Self-Report (YSR) was used to obtain selfreports on emotional and behavioural problems. The Child Behavior Checklist (CBCL) was used for parent-reports. The questionnaires are interrelated and have good validity [3]. Respondents were asked to rate the occurrence of problems in the preceding 6 months. The YSR consists of 102 items and the CBCL consists of 118 items, scored on a three-point response scale: $0=$ not true, $1=$ somewhat or sometimes true and $2=$ very true or often true. The items are scored on eight syndrome scales as defined by Achenbach [2]: Withdrawn, Somatic Complaints, Anxious/ Depressed, Social Problems, Thought Problems, Attention Problems, Delinquent Behaviour and Aggressive Behaviour. The sum of scores of the first three syndromes indicates the broadband scale Internalizing, and the sum of scores on 
the Delinquent and Aggressive Behaviour syndromes indicates the broadband scale Externalizing. All problem items are summed to calculate a Total Problems score. The CBCL and YSR were revised in 2001 and these versions were used in the Dutch general population sample. Since data of the Moroccan immigrant sample were already available at the start of the present study and the older versions of the YSR and CBCL (1991) had been used in that study, we decided to use these older versions in the incarcerated sample as well. In the present paper, we analysed the items that were in all versions for all samples. Therefore, we excluded five new items in the Dutch general population sample. One item in the earlier versions ('I use alcohol or drugs') was separated into two questions ('I use alcohol' and 'I use drugs'). Therefore, we calculated a combination score of the two items for the Dutch general population sample, based on the highest score of the two questions, see also [22].

In order to interview the parents in the Moroccan samples, the CBCL was translated into Moroccan-Arabic. Reliabilities of the Moroccan-Arabic translation of the CBCL were comparable to the reliabilities of the Dutch version. The alphas of most syndrome scales range from 0.56 to 0.88 ; the alphas of the broadband scales range from 0.82 to 0.89 . Since all adolescent participants received Dutch education, we used the Dutch versions of the YSR in all adolescent samples. Good reliabilities for the Dutch YSR and CBCL have been established elsewhere [26, 27].

\section{Socio-economic status}

To determine the socio-economic status (SES) of the participants, postal codes of their parents' homes were used. The Netherlands Social and Cultural Planning Office calculates SES scores (which are based on mean income, education level, percentage unemployed and percentage households per neighbourhood) for all postal codes in the Netherlands. These SES scores are originally provided in an order number (0-4) with three decimal places [12]; we classified the scores into low (0-1), medium (1-3) and high (3-4) SES.

\section{Social desirability}

To assess a social desirable response style, incarcerated subjects and their parents were provided a 10-item version of the Marlowe-Crowne Social Desirability Scale [20]. Two examples of the items include "I have never intensely disliked anyone" and "I like to gossip at times." The items refer to socially approved but uncommon behaviours and socially disapproved but common behaviours. Each item is scored as true or false. Social desirable answers are assigned a score of 1 , answers which are not social desirable are assigned a score of 0 . The score for each subject is the sum of scores from the individual items. The reliability and clinical utility of The Marlowe-Crowne Social Desirability Scale in forensic settings has been established elsewhere [4].

\section{Offender type}

To assess the offence history of the participants, police records were gathered at The Dutch Ministry of Justice. The records contain information on type of offence(s) committed in the past (offences as formulated in youth criminal law), and age at first offence. We classified the incarcerated adolescents into four different offender categories, see [25]; Property offenders, Sexual offenders, Violent offenders and Arsonists. In the present study, Sexual offenders, Violent offenders and Arsonists were considered as Serious offenders and Property offenders were considered as Non-serious offenders.

\section{Statistical analyses}

Ethnic differences in mental health problems among incarcerated and general population youth of native Dutch and Moroccan origin were tested by conducting multigroup analyses. To account for non-normal distributed data and non-homogeneity of covariance matrices of the dependent variables, analyses were conducted in the software package Mplus version 5 which enables non-parametric testing. Chi-square difference testing was applied to demonstrate the differences between the groups. To control for the dependent variables in each analysis, we first entered the syndrome scales simultaneously in a separate analysis, then we analysed the broadband scales simultaneously in another separate analysis, and finally we analysed the total problem scale separately. We tested whether interaction effects between ethnicity (native Dutch and Moroccan) and population (general population and incarcerated population) on mental health problems were present using multiple regression analyses. To control for age and SES, these variables were included as covariates in all analyses. To control for the possible effects of social desirability on ethnic differences in mental health in incarcerated youth, we included this variable as a covariate in the analyses on incarcerated youths. Finally, we tested differences in the level of mental health problems between serious offenders and non-serious offenders using MANOVA's.

\section{Results}

\section{Descriptives}

Table 1 shows age, SES and the mean scores on the Marlowe-Crowne Social Desirability Scale for each group. 
Table 1 Mean age, socio-economic status and social desirability (SD)

\begin{tabular}{lllll}
\hline & Age & SES & $\begin{array}{l}\text { Social desirability } \\
\text { adolescents }\end{array}$ & $\begin{array}{c}\text { Social desirability } \\
\text { parents }\end{array}$ \\
\hline GPD,$N=304$ & $15.60^{\mathrm{d}}(1.85)$ & $2.11^{\mathrm{d}}(0.71)$ & - & - \\
$\mathrm{GPM}, N=142$ & $15.20^{\mathrm{a}}(1.71)$ & $1.04^{\mathrm{a}}(0.18)$ & - & - \\
$\mathrm{ID}, N=156$ & $16.12^{\mathrm{c}}(1.22)$ & $1.81^{\mathrm{c}}(0.69)$ & $5.3^{\mathrm{a}}(1.92)$ & $7.1^{\mathrm{a}}(1.72)$ \\
$\mathrm{IM}, N=139$ & $15.82^{\mathrm{b}, \mathrm{c}}(1.23)$ & $1.40^{\mathrm{b}}(0.61)$ & $6.7^{\mathrm{b}}(2.15)$ & $9.0^{\mathrm{b}}(1.17)$ \\
\hline
\end{tabular}

$G P D$ general population Dutch, GPM general population Moroccan, $I D$ incarcerated Dutch, $I M$ incarcerated Moroccan

Different superscript letters refer to significant differences $(P<0.05)$ between the groups (within columns)

Table 2 Self-reported symptoms, estimated sample mean

\begin{tabular}{|c|c|c|c|c|c|c|c|c|c|c|c|}
\hline & WTH & SOM & AXD & ADD & THT & SOC & DEL & AGG & INT & EXT & Total problems \\
\hline GPD, $N=304$ & $2.480^{\mathrm{b}}$ & $1.609^{\mathrm{a}}$ & $3.398^{\mathrm{a}}$ & $4.628^{\mathrm{b}}$ & $1.609^{c}$ & $2.243^{\mathrm{a}, \mathrm{b}}$ & $3.332^{\mathrm{a}}$ & $6.437^{\mathrm{a}}$ & $7.332^{\mathrm{b}}$ & $9.770^{\mathrm{a}}$ & $29.164^{\mathrm{b}}$ \\
\hline GPM, $N=142$ & $2.077^{\mathrm{a}}$ & $1.606^{\mathrm{a}}$ & $3.500^{\mathrm{a}}$ & $2.972^{\mathrm{a}}$ & $0.570^{\mathrm{a}}$ & $1.838^{\mathrm{a}}$ & $3.007^{\mathrm{a}}$ & $5.592^{\mathrm{a}}$ & $7.014^{\mathrm{a}}$ & $8.599^{\mathrm{a}}$ & $23.310^{\mathrm{a}}$ \\
\hline $\mathrm{ID}, N=156$ & $3.308^{\mathrm{c}}$ & $2.679^{\mathrm{b}}$ & $6.128^{\mathrm{b}}$ & $6.429^{c}$ & $2.404^{\mathrm{d}}$ & $2.462^{\mathrm{b}}$ & $7.878^{\mathrm{c}}$ & $10.359^{b}$ & $11.692^{\mathrm{c}}$ & $18.237^{b}$ & $46.436^{\mathrm{c}}$ \\
\hline $\mathrm{IM}, N=139$ & $2.914^{\mathrm{b}, \mathrm{c}}$ & $2.273^{\mathrm{b}}$ & $3.978^{\mathrm{a}}$ & $3.468^{\mathrm{a}}$ & $1.144^{\mathrm{b}}$ & $2.144^{\mathrm{a}, \mathrm{b}}$ & $4.453^{\mathrm{b}}$ & $5.360^{\mathrm{a}}$ & $8.906^{\mathrm{b}}$ & $9.813^{\mathrm{a}}$ & $28.885^{\mathrm{b}}$ \\
\hline
\end{tabular}

GPD general population Dutch, GPM general population Moroccan, ID incarcerated Dutch, IM incarcerated Moroccan, WTH Withdrawn, SOM Somatic Complaints, AXD Anxious/Depressed, ADD Attention Problems, THT Thought Problems, SOC Social Problems, DEL Delinquent Behaviour, $A G G$ Aggressive Behaviour, INT Internalizing, EXT Externalizing

Different superscript letters refer to significant differences $(P<0.05)$ between the groups (within columns), controlled for age and SES

SES differed significantly between each group $(F=111.83, d f=3, P<0.01)$. Also, Moroccan incarcerated boys scored significantly higher on the MarloweCrowne Social Desirability Scale than native Dutch incarcerated boys $(F=35.41, d f=1, P<0.00)$. Likewise, Moroccan parents with an incarcerated son scored significantly higher on the Marlowe-Crowne Social Desirability Scale than native Dutch parents with an incarcerated son $(F=72.66, d f=1, P<0.00)$. Social desirability correlated significantly negatively with the Total Problems of the Youth Self-Report $(r=-0.54)$ and the Total Problems of the Child Behavior Checklist $(r=-0.32)$.

\section{Self-reported symptoms}

Table 2 shows the mean scores on all YSR scales (dependent variables) for each group, controlled for age and SES. To test whether the mean scores differed between the groups, a multigroup testing procedure was used. First, in the overall model, a baseline Chi-square was computed with no equality constraints for all groups on all YSR syndrome scales $\left(\chi^{2}=77,239, d f=48\right.$; unconstrained model). Next, the dependent variables were constrained to be equal for all groups on each of the syndrome scales and the Chi-square was calculated $\left(\chi^{2}=362,184, d f=72\right.$; constrained model). The Chi-square difference between the unconstrained and constrained model revealed that the four groups scored significantly different on the syndrome scales of the YSR $\left(\Delta \chi^{2}=284,945, d f=24, P<0.01\right)$. The same Chi-square difference testing procedure was used for the scores on the broadband scales and the Total Problems scale, again the Chi-square difference tests indicated that the four groups differed on these YSR scales. To test which scale scores differed between which groups, we used the same Chi-square difference testing procedure with the unconstrained model as the baseline model and a model in which we systematically constrained the scores on each syndrome scale, the broadband scales and the Total Problems score between two groups. This resulted in six comparisons for each scale, thus in total 66 Chi-square tests.

Compared to youth offenders of Moroccan origin, Dutch native offenders scored higher on the Anxious/ Depressed, Attention Problems, Thought Problems, Delinquent and Aggressive Behaviour syndrome scales, on the Internalizing and Externalizing broadband scales and on the Total Problems scale. These differences remained significant when corrected for social desirability; Anxious/ Depressed $(F=7.392, \quad d f=1, \quad P=0.01), \quad$ Attention Problems $(F=28.216, d f=1, P=0.00)$, Thought Problems $(F=18.808, d f=1, P=0.00)$, Delinquent Behaviour $(F=31.635, d f=1, P=0.00)$, Aggressive Behaviour $(F=27.228, d f=1, P=0.00)$, Internalizing $(F=4.424$, $d f=1, P=0.04)$, Externalizing $(F=38.013, d f=1$, $P=0.00)$ and Total Problems $(F=25.002, d f=1$, $P=0.00)$. Effect sizes for above differences varied from small to medium effects; Anxious/Depressed $\left({ }_{\mathrm{p}} \eta^{2}=0.03\right)$, 
Table 3 Main- and interaction effects on self-reported symptoms

\begin{tabular}{|c|c|c|c|c|c|c|c|c|c|c|c|}
\hline & WTH & SOM & AXD & ADD & THT & SOC & DEL & AGG & INT & EXT & Total problems \\
\hline Ethnicity & $-0.103 *$ & -0.075 & $-0.127 *$ & $-0.343^{*}$ & $-0.299 *$ & $-0.095^{*}$ & $-0.246^{*}$ & $-0.252^{*}$ & $-0.129 *$ & $-0.273 *$ & $-0.281 *$ \\
\hline Incarceration & $0.172 *$ & $0.211^{*}$ & $0.210^{*}$ & $0.191 *$ & $0.169 *$ & 0.070 & $0.467 *$ & $0.209^{*}$ & $0.238^{*}$ & $0.341^{*}$ & $0.312 *$ \\
\hline Interaction & 0.010 & -0.033 & $-0.133 *$ & $-0.106^{*}$ & -0.026 & 0.012 & $-0.235^{*}$ & $-0.212^{*}$ & $-0.081 *$ & $-0.242^{*}$ & $-0.157 *$ \\
\hline
\end{tabular}

Beta-weights are corrected for age and SES. Beta-weights of the interaction effects are corrected for age, SES and the main effects of ethnicity and population. Ethnicity (native Dutch $=0$, Moroccan immigrant $=1$ ); incarceration (general population $=0$, incarcerated population $=1$ ) WTH Withdrawn, SOM Somatic Complaints, AXD Anxious/Depressed, ADD Attention Problems, THT Thought Problems, SOC Social Problems, $D E L$ Delinquent Behaviour, AGG Aggressive Behaviour, INT Internalizing, EXT Externalizing

* Significant main effect of ethnicity (Moroccan immigrant or native Dutch), being incarcerated or not (general population or incarcerated population), or a significant interaction effect between ethnicity and incarceration on the eight syndrome scales, the broadband scales and the Total Problems score, $P<0.05$

Table 4 Parent-reported symptoms, estimated sample mean

\begin{tabular}{|c|c|c|c|c|c|c|c|c|c|c|c|}
\hline & WTH & SOM & AXD & ADD & THT & SOC & DEL & AGG & INT & EXT & Total problems \\
\hline GPD, $N=293$ & $2.321^{\mathrm{a}}$ & $1.034^{\mathrm{a}}$ & $2.577^{\mathrm{a}}$ & $3.679^{\mathrm{b}}$ & $0.464^{\mathrm{a}}$ & $1.443^{\mathrm{b}}$ & $1.717^{\mathrm{a}}$ & $4.874^{\mathrm{a}}$ & $5.802^{\mathrm{a}}$ & $6.590^{\mathrm{a}}$ & $21.392^{\mathrm{a}}$ \\
\hline GPM, $N=138$ & $2.493^{\mathrm{a}}$ & $1.087^{\mathrm{a}}$ & $2.942^{\mathrm{a}}$ & $2.891^{\mathrm{a}}$ & $0.384^{\mathrm{a}}$ & $1.116^{\mathrm{a}}$ & $2.478^{\mathrm{b}}$ & $5.928^{\mathrm{a}, \mathrm{b}}$ & $6.384^{\mathrm{a}}$ & $8.406^{\mathrm{a}, \mathrm{b}}$ & $20.935^{\mathrm{a}}$ \\
\hline $\mathrm{ID}, N=76$ & $4.224^{\mathrm{b}}$ & $1.803^{\mathrm{b}}$ & $6.224^{\mathrm{b}}$ & $7.724^{\mathrm{d}}$ & $1.763^{\mathrm{b}}$ & $3.145^{\mathrm{c}}$ & $8.500^{\mathrm{d}}$ & $12.776^{\mathrm{c}}$ & $11.632^{\mathrm{b}}$ & $21.276^{\mathrm{c}}$ & $48.382^{\mathrm{b}}$ \\
\hline $\mathrm{IM}, N=87$ & $3.414^{\mathrm{b}}$ & $1.402^{\mathrm{a}, \mathrm{b}}$ & $6.345^{\mathrm{b}}$ & $5.057^{\mathrm{c}}$ & $0.529^{\mathrm{a}}$ & $1.621^{\mathrm{b}}$ & $3.448^{\mathrm{c}}$ & $6.713^{\mathrm{b}}$ & $10.678^{b}$ & $10.161^{\mathrm{b}}$ & $30.161^{c}$ \\
\hline
\end{tabular}

GPD general population Dutch, GPM general population Moroccan, ID incarcerated Dutch, IM incarcerated Moroccan, WTH Withdrawn, SOM Somatic Complaints, AXD Anxious/Depressed, ADD Attention Problems, THT Thought Problems, SOC Social Problems, DEL Delinquent Behaviour, $A G G$ Aggressive Behaviour, INT Internalizing, EXT Externalizing

Different superscript letters refer to significant differences $(P<0.05)$ between the groups (within columns), controlled for age of adolescent and SES

Attention Problems $\left({ }_{\mathrm{p}} \eta^{2}=0.09\right)$, Thought Problems $\left({ }_{\mathrm{p}} \eta^{2}=0.06\right)$, Delinquent Behaviour $\left({ }_{\mathrm{p}} \eta^{2}=0.10\right)$, Aggressive Behaviour $\left({ }_{\mathrm{p}} \eta^{2}=0.09\right.$, Internalizing $\left({ }_{\mathrm{p}} \eta^{2}=0.02\right.$, Externalizing $\left(\mathrm{p}^{2}=0.12\right)$ and Total Problems $\left({ }_{\mathrm{p}} \eta^{2}=0.08\right)$. Also, compared to the general population, Dutch native incarcerated youths reported more problems on all but one scale (Social Problems) than non-incarcerated native Dutch youths. Incarcerated youths of Moroccan origin reported significantly more Withdrawn Behaviour, Somatic Complaints, Thought Problems and Delinquent Behaviour, Internalizing and Total Problems than non-incarcerated youths of Moroccan origin.

Furthermore, we tested whether interaction effects between ethnicity and population on the YSR scales were present. The Beta-weights of the main and interaction effects, corrected for age and SES are shown in Table 3. Interaction effects were found for the following YSR scales: Anxious/Depressed, Attention Problems, Delinquent Behaviour and Aggressive Behaviour, Internalizing, Externalizing and Total Problems, generally showing that incarcerated youths experience higher levels of mental health problems than youths in the general population, and that these differences are much larger for Dutch youths than for Moroccan youths.
Parent-reported symptoms

Table 4 shows the mean scores on all CBCL scales for each group, controlled for age of the adolescent and SES. The four groups scored significantly different on the CBCL scales $\left(\Delta \chi^{2}=157,003, d f=24, P<0.01\right)$. To test which scale scores differed between which groups, the same Chi-square difference testing was used as with the self-reported data.

Compared to parents of Moroccan origin, native Dutch parents reported their incarcerated sons as showing significantly more Attention Problems, Thought Problems, Social Problems, Delinquent and Aggressive Behaviour, Externalizing and Total Problems. These differences remained significant when corrected for social desirability; Attention Problems $(F=6.963, \quad d f=1, \quad P=0.01)$, Thought Problems $(F=8.212, d f=1, P=0.01)$, Social Problems $(F=7.107, \quad d f=1, \quad P=0.01)$, Delinquent Behaviour $(F=22.662, d f=1, P=0.00)$, Aggressive Behaviour $(F=7.683, d f=1, P=0.00)$, Externalizing $(F=13.989, \quad d f=1, \quad P=0.00)$ and Total Problems $(F=8.394, d f=1, P=0.00)$. Effect sizes for above differences varied from small to medium effects; Attention Problems $\left({ }_{\mathrm{p}} \eta^{2}=0.04\right)$, Thought Problems $\left({ }_{\mathrm{p}} \eta^{2}=0.05\right)$, Social Problems $\left({ }_{\mathrm{p}} \eta^{2}=0.05\right)$, Delinquent Behaviour 
Table 5 Main- and interaction effects on parent-reported symptoms

\begin{tabular}{lrlllllllllll}
\hline & WTH & SOM & AXD & ADD & THT & SOC & DEL & AGG & INT & EXT & Total problems \\
\hline Ethnicity & -0.031 & -0.027 & -0.001 & $-0.217^{*}$ & $-0.178^{*}$ & $-0.202^{*}$ & $-0.201^{*}$ & $-0.116^{*}$ & -0.017 & $-0.155^{*}$ & $-0.181^{*}$ \\
Incarceration & $0.257^{*}$ & $0.138^{*}$ & $0.424^{*}$ & $0.381^{*}$ & $0.269^{*}$ & $0.266^{*}$ & $0.474^{*}$ & $0.320^{*}$ & $0.366^{*}$ & $0.397^{*}$ & $0.406^{*}$ & $-0.13 *$ \\
Interaction & $-0.093^{*}$ & -0.059 & -0.005 & $-0.112^{*}$ & $-0.227^{*}$ & $0.136^{*}$ & $-0.359^{*}$ & $-0.261^{*}$ & -0.053 & $-0.313^{*}$ & $-0.199^{*}$ & \\
\hline
\end{tabular}

Beta-weights are corrected for age and SES. Beta-weights of the interaction effects are corrected for age, SES and the main effects of ethnicity and population. Ethnicity (native Dutch $=0$, Moroccan immigrant $=1$ ); incarceration (general population $=0$, incarcerated population $=1$ ) WTH Withdrawn, SOM Somatic Complaints, AXD Anxious/Depressed, ADD Attention Problems, THT Thought Problems, SOC Social Problems, $D E L$ Delinquent Behaviour, $A G G$ Aggressive Behaviour, INT Internalizing, EXT Externalizing

* Significant main effect of ethnicity (Moroccan immigrant or native Dutch), being incarcerated or not (general population or incarcerated population), or a significant interaction effect between ethnicity and incarceration on the eight syndrome scales, the broadband scales and the Total Problems score, $P<0.05$

$\left({ }_{\mathrm{p}} \eta^{2}=0.13\right)$, Aggressive Behaviour $\left({ }_{\mathrm{p}} \eta^{2}=0.05\right.$, Externalizing $\left({ }_{\mathrm{p}} \eta^{2}=0.09\right)$ and Total Problems $\left({ }_{\mathrm{p}} \eta^{2}=0.05\right)$. Also, parents of native Dutch incarcerated youths reported more problems on all scales than parents of general population native Dutch youths. Moroccan parents of incarcerated youths reported their sons as showing significantly more Withdrawn Behaviour, Anxious/Depressed symptoms, Attention Problems, Social Problems, Delinquent Behaviour, Internalizing and Total Problems than parents of non-incarcerated Moroccan youths.

Next, we tested interaction effects between ethnicity and population on all CBCL scales (see Table 5). Interaction effects were found for the following scales: Withdrawn, Attention Problems, Thought Problems, Social Problems, Delinquent Behaviour and Aggressive Behaviour, Externalizing and Total Problems, again showing that parents of incarcerated youths report higher levels of these mental health problems than parents of youths in the general population, and that these differences are much larger for Dutch youths than for Moroccan youths.

Finally, since some of the findings may have been biased because of incomplete sampling of the parents in the incarcerated population, we tested if adolescents whose parents completed the interview, scored significantly different on the broadband scales of the YSR from adolescents whose parents did not participate in the study. No significant differences were found on the Internalizing scale $(F=0.392, d f=1, P=0.53)$ or the Externalizing scale $(F=1.106, d f=1, P=0.29)$.

Mental health problems and offender type

Serious offenders in the incarcerated sample scored significantly higher on Externalizing $(M=16.18, \mathrm{SD}=8.23)$ than Non-serious offenders $(M=12.94, \quad \mathrm{SD}=8.88$; $F=9.962, d f=1, P=0.00)$. Serious offenders did not score significantly higher on Internalizing $(M=11.46$, $\mathrm{SD}=7.79)$ than Non-serious offenders $(M=9.77$, $\mathrm{SD}=7.99 ; F=3.225, d f=1, P=0.07)$. In addition, the difference on Externalizing did not remain significant when controlling for ethnicity $(F=0.005, d f=1, P=0.95)$. Likewise, parents of Serious offenders reported significantly higher scores on Externalizing $(M=17.78$, $\mathrm{SD}=14.04)$ than parents of Non-serious offenders $(M=13.64, \mathrm{SD}=11.92 ; F=4.043, d f=1, P=0.05)$, and the scores for Internalizing were not higher for Serious offenders $(M=11.05, \mathrm{SD}=7.85)$ than for Non-serious offenders $(M=11.10, \mathrm{SD}=6.97 ; \quad F=0.002, d f=1$, $P=0.96)$. Finally, in accordance with the self-reported scores, the difference on Externalizing reported by the parents did not remain significant when controlling for ethnicity $(F=0.204, d f=1, P=0.65)$.

\section{Discussion}

The purpose of this study was to examine ethnic differences in mental health problems among incarcerated boys of native Dutch and Moroccan origin. As expected, analysis of self- and parent-reported mental health problems showed that native Dutch offenders had significantly more mental health problems compared to youth offenders of Moroccan origin. In line with previous US research, native Dutch adolescent offenders showed higher levels of mental health problems overall, and more Anxious/Depressed symptoms, Attention Problems, Thought Problems, Social Problems, Delinquent Behaviour and Aggressive Behaviour in particular. Next, a clear difference between incarcerated and general population youths was found. Incarcerated youths were at increased risk of virtually all CBCL and YSR problem scales. However, differences between general population and incarcerated youths were much larger for native Dutch than for Moroccan immigrant youths, as was indicated by several interaction effects between ethnicity and population. Whereas native Dutch incarcerated youths showed much higher levels of psychopathology than their peers in the general population, these differences were small for Moroccan immigrant youths. 
How can we explain these differences in mental health problems between Dutch native and Moroccan immigrant youth? First, ethnic minority youths are often brought up in situations of socio-economic disadvantage, which have been suggested as main determinants of the increased risk for ethnic minority youths to get engaged in criminal behaviour [13, 24], However, ethnic differences in mental health problems did not disappear when controlling for SES in the present study. Although some residual effect of SES may still have been present, this finding is in line with earlier studies which showed that straightforward differences in SES between ethnic minority and majority groups do not explain the differences in problem behaviour between ethnic minority and majority youth [19].

Second, the lower level of mental health problems of ethnic minority youth offenders may be the result of social desirability bias: both adolescents and parents with an ethnic minority background possibly underreport mental health problems as they are aware of their low status in society, and do not want to confirm the negative perception about their children or themselves [7, 18]. In the present study, ethnic differences between incarcerated Moroccan and native Dutch youths remained significant when corrected for social desirability bias, which is an indication against this second hypothesis. However, despite the statistical correction for this response style, underreporting of problems due to a social desirable bias may still have been present. Since we compared ethnic differences in the incarcerated group with ethnic differences in the general population, we therefore controlled for a general ethnic tendency of answering in a social desirable way.

Third, an alternative explanation for the lower levels of mental health problems of incarcerated minority adolescents, is that these youths may not be treated the same as ethnic majority youths in the juvenile justice system [8, 14]. In fact, it has been found that minority youths are referred to juvenile court and are taken into pre-trial arrest for less serious offences than ethnic majority youths [8, 15]. As less serious offences may be associated with lower levels of psychiatric symptoms [16], incarcerated ethnic minority youths entering the juvenile justice system may reveal fewer psychiatric symptoms than incarcerated ethnic majority youths [30]. Furthermore, we previously found that Moroccan adolescent offenders in the Netherlands represent a specific offender type in youth crime [25]. Our analysis of police record data showed that Moroccans were incarcerated more often for property-based offences, and less often for more serious offences such as violent and sexual offences and arson, than native Dutch adolescents. This offending pattern of Moroccan incarcerated adolescents may be the result of a higher prevalence of less serious delinquency in these youths, but it could also be the result of disparities in juvenile justice practice [15]. In the present study, we initially found a relationship between serious offender types and higher levels of externalizing problems. However, this relationship does not offer an explanation for the ethnic differences in mental health problems in the incarcerated population. In fact, native Dutch incarcerated boys seem to report higher levels of mental health problems than Moroccan incarcerated boys, irrespective of their serious offending behaviour. Thus, ethnic differences in mental health problems of incarcerated adolescent coexist with ethnic differences in offending behaviour.

The present study was the first examining ethnic differences in mental health problems between incarcerated and general population youths, using a four group design. Some limitations of this study should be mentioned. First, the cross-sectional nature of the study makes it difficult to examine causal pathways between ethnic differences in mental health problems of incarcerated youths and explanatory variables such as SES. Yet, due to the design of this study, it was possible to use the level of mental health problems of different ethnic groups from the general population as a benchmark. Inter- and intra-cultural comparisons of mental health problems between incarcerated and general population youths strengthen the findings of this study.

Second, as information on sentencing processes was not at hand, we were unable to examine the effect of disparities in juvenile justice procedures on the large discrepancy of mental health problems between Moroccan immigrant and native Dutch youths in juvenile justice institutions. Third, due to practical considerations we did not include diagnostic interviews or teacher report forms in the present study. The level of mental health problems measured by self-report instruments may to some extent be subject to social desirability (i.e. biased self-presentation). However, in contrast to most studies on self-reported mental health problems in incarcerated samples, we included additional parent-reported information on the mental health of the subjects. Moreover, we corrected for social desirability bias in the incarcerated population and showed that ethnic differences between incarcerated Moroccan and native Dutch youths remained significant.

Fourth, previous research has indicated that although Moroccan youth and their parents in the general population report lower CBCL and YSR scores than Dutch youth, their teachers report higher problem scores [18]. This means that Moroccan parents and adolescents may underreport problems relative to Dutch parents and adolescents, but that teachers' reports indicate more problems for Moroccan youth. However, it may also be possible that teachers report higher problem scores because of ethnic prejudice. Given the findings in the present study, in which a general social desirable tendency was controlled by comparing 
ethnic differences in the incarcerated and in the general population, it seems that incarcerated Moroccan youth indeed do have fewer problems than incarcerated Dutch youth.

Fifth, it is important to note that the time difference between the collection of data in the incarcerated sample and the general population samples, may have affected findings. However, previous research showed that problem scores of children and adolescents in the general population did not change significantly over a 10 -year time period [28], which is an indication against the possible influence of time differences in data collection. Also, we had to eliminate five items from the YSR and CBCL in the analyses since our data included two different versions. Although this may have caused a minimal loss of information, in previous research the two versions provided comparable scores [e.g. 22, 23]. Finally, the response rates of the incarcerated adolescents and their parents were modest compared to the response rates in the general population samples. This may have biased findings as lower response rates are generally associated with lower scores.

In conclusion, our findings indicate that native Dutch adolescent offenders show higher levels of mental health problems than incarcerated adolescents with an ethnic minority (Moroccan) background. Indeed, in comparison with the general population, incarcerated youths show higher levels of mental health problems, but this deviation is much larger for native Dutch youths than for Moroccan youths. Both self- and parent reported data offer strong support for these conclusions. Overall, it seems that native Dutch adolescent offenders report both higher levels of mental health problems and also commit more serious offences than Moroccan adolescent incarcerated boys. The differences in mental health problems may have clinical implications. For instance, native Dutch incarcerated youth may need relatively more mental health care in comparison to Moroccan incarcerated youth. In contrast, Moroccan incarcerated youth may need other forms of support, such as more intensive educational training, to enhance their chances on the labour market and hereby decreasing the risk of becoming involved in crime. Finally, since we controlled for socio-economic background and social desirability bias, we hypothesize that disparities in sentencing procedures may play a role in the incarceration of ethnic minority youths with relatively lower levels of mental health problems. Future research is needed to further unravel the influence of sentencing procedures, as this may have implications for the practice of juvenile justice.

Acknowledgments This work was supported by a grant from the Netherlands Organization for Scientific Research (NWO) and Utrecht University.
Open Access This article is distributed under the terms of the Creative Commons Attribution Noncommercial License which permits any noncommercial use, distribution, and reproduction in any medium, provided the original author(s) and source are credited.

\section{References}

1. Abram KM, Teplin LA, McClelland GM, Dulcan MK (2003) Comorbid psychiatric disorders in youth in juvenile detention. Arch Gen Psychiatry 60:1097-1108

2. Achenbach TM (1991) Manual for the child behavior checklist/ 4-18 and 1991 profile. University of Vermont, Department of Psychiatry, Burlington

3. Achenbach TM, Rescorla LA (2001) Manual for the ASEBA school-age forms and profiles. University of Vermont: Research Center for Children, Youth and Families, Burlington

4. Andrews P, Meyer RG (2003) Marlowe-Crowne social desirability scale and short form C: forensic norms. J Clin Psychol 59:483-492

5. Blom M, Oudhof J, Bijl RV, Bakker BFM (2005) Verdacht van criminaliteit: Allochtonen en autochtonen nader bekeken [Crime suspect: a closer look on ethnic minorities and native Dutch]. Wetenschappelijk Onderzoek- en Documentatiecentrum, The Hague

6. Boendermaker L (1995) Jongeren in justitiële behandelinrichtingen [Youths in juvenile justice treatment institutions]. Wetenschappelijk Onderzoek- en Documentatiecentrum, The Hague

7. Cauffman E (2004) A statewide screening of mental health symptoms among juvenile offenders in detention. J Am Acad Child Adolesc Psychiatry 43:430-439

8. Engen RL, Steen S, Bridges GS (2002) Racial disparities in the punishment of youth: a theoretical and empirical assessment of the literature. Soc Probl 49:194-220

9. Fazel S, Doll H, Langstrom N (2008) Mental disorders among adolescents in juvenile detention and correctional facilities: a systematic review and metaregression analysis of 25 surveys. J Am Acad Child Adolesc Psychiatry 47:1010-1019

10. Hamerlynck S (2008) Girls in juvenile justice institutions: psychopathology and sexual risk behavior. Symfora Groep, VU University, Amsterdam

11. Karnik NS, Jones PA, Campanaro AE, Haapanen R, Steiner H (2006) Ethnic variation of self-reported psychopathology among incarcerated youth. Community Ment Health J 42:477-486

12. Knol FA (1998) Van hoog naar laag, van laag naar hoog: De sociaalruimtelijke ontwikkeling van wijken [From high to low, from low to high: the social and environmental development of neighbourhoods]. Sociaal Cultureel Planbureau, The Hague

13. McNulty TL, Bellair PE (2003) Explaining racial and ethnic differences in serious adolescent violent behavior. Criminology 41:709-748

14. Mustard DB (2001) Racial, ethnic, and gender disparities in sentencing: evidence from the U.S. Federal Courts. J Law Econ 44:285-315

15. Rodney HE, Tachia HR (2004) Over-representation of minorities in the juvenile justice system: three counties in rural Texas. Fed Probat 68:44-48

16. Sheidow AJ, Strachan MK, Minden JA, Henry DB, Tolan PH, Gorman-Smith D (2008) The relation of antisocial behavior patterns and changes in internalizing symptoms for a sample of inner-city youth: comorbidity within a developmental framework. J Youth Adolesc 37:821-829

17. Sickmund M, Sladky TJ, Kang W (2008) Census of juveniles in residential placement databook. Available at: http://www.ojjdp. ncjrs.gov/ojstatbb/cjrp 
18. Stevens GW, Pels T, Bengi-Arslan L, Verhulst FC, Vollebergh WA, Crijnen AA (2003) Parent, teacher and self-reported problem behavior in the Netherlands: comparing Moroccan immigrant with Dutch and with Turkish immigrant children and adolescents. Soc Psychiatry Psychiatr Epidemiol 38:576-585

19. Stevens GW, Vollebergh WA (2008) Mental health in migrant children. J Child Psychol Psychiatry 49:276-294

20. Strahan R, Gerbasi KC (1972) Short, homogeneous versions of the Marlow-Crowne social desirability scale. J Clin Psychol 28:191-193

21. Teplin LA, Abram KM, McClelland GM, Dulcan MK, Mericle AA (2002) Psychiatric disorders in youth in juvenile detention. Arch Gen Psychiatry 59:1133-1143

22. Tick NT, van der Ende J, Verhulst FC (2008) Ten-year trends in self-reported emotional and behavioral problems of Dutch adolescents. Social Psychiatry and Psychiatric Epidemiology

23. Tick NT, van der Ende J, Verhulst FC (2007) Twenty-year trends in emotional and behavioral problems in Dutch children in a changing society. Acta Psychiatr Scand 116:473-482

24. Vaughn MG, Wallace JM Jr, Davis LE, Fernandes GT, Howard MO (2008) Variations in mental health problems, substance use, and delinquency between African American and Caucasian juvenile offenders: implications for reentry services. Int $\mathbf{J}$ Offender Ther Comp Criminol 52:311-329

25. Veen VC, Stevens GWJM, Doreleijers TA, Vollebergh WAM (in press) Moroccan adolescent suspect offenders in the Netherlands: Ethnic differences in offender profiles. Psychol Crime Law
26. Verhulst FC, van der Ende J, Koot H (1997) Handleiding voor de Youth Self-Report (YSR) [Manual for the youth self-report]. Department of child and Adolescent Psychiatry, Erasmus Medical Centre/Sophia, Rotterdam

27. Verhulst FC, van der Ende J, Koot HM (1996) Handleiding voor de CBCL/ 4-18 [Manual for the CBCL/ 4-18]. Department of Child and Adolescent Psychiatry, Erasmus Medical Centre/ Sophia, Rotterdam

28. Verhulst FC, van der Ende J, Rietbergen A (1997) Ten-year time trends of psychopathology in Dutch children and adolescents: No evidence for strong trends. Acta Psychiatr Scand 96:7-13

29. Vincent GM, Grisso T, Terry A, Banks S (2008) Sex and race differences in mental health symptoms in juvenile justice: the MAYSI-2 national meta-analysis. J Am Acad Child Adolesc Psychiatry 47:282-290

30. Vreugdenhil C, Doreleijers TA, Vermeiren R, Wouters LF, van den Brink W (2004) Psychiatric disorders in a representative sample of incarcerated boys in the Netherlands. J Am Acad Child Adolesc Psychiatry 43:97-104

31. Wasserman GA, McReynolds LS, Lucas CP, Fisher P, Santos L (2002) The voice DISC-IV with incarcerated male youths: prevalence of disorder. J Am Acad Child Adolesc Psychiatry $41: 314-321$ 